\title{
Identification and assessment of hazard in the Refractory Brick Production Company of Gonabad, Iran, using the hazard and operability technique
}

\author{
Azrah K, Msc' ${ }^{1}$ Jamali Z, Bsc² ${ }^{2}$ Jari A, Bsc ${ }^{* 2}$ \\ 1- Faculty Member, Dept. of Occupational Health Engineering, School of Public Health, Gonabad University of Medical \\ Sciences, Gonabad, Iran. 2- Student Research Committee, Dept. of Occupational Health Engineering, School of Public \\ Health, Gonabad University of Medical Sciences, Gonabad, Iran.
}

\begin{abstract}
Received: June 2015, Accepted: August 2015

Background: In the refractory brick manufacturing industry, because of the high risks associated with the level of dust in the factory environment and thermal stress, a precise identification of industrial hazards is required as a part of safety analysis. The aim of this study was to introduce a preventive approach to risk identification and assessment in the refractory brick production line.

Materials and Methods: In this paper, methods such as observation of factory operations, process analysis through the factory diagrams, and interviews with employees were used. In addition, the risk levels of the factory were investigated using the risk matrix.

Results: The results of the study showed 97 deviations from the main process with various causes and consequences. None of the deviations were in the unacceptable category with 3.09\% falling in the undesirable category, $3.09 \%$ in the acceptable but in need of revision category, and $92.78 \%$ in the acceptable category.

Conclusions: The results showed that $40.2 \%$ of the risks were caused by human errors. The installation of a secondary control valve in the transfer route of the glue vapors to the workplace, an alternative pressure control system, a secondary ventilation system, several fans near the furnace (redundancy), and a real-time phenol monitor are recommended. Moreover, regular analysis of safety, health, and environmental risks are some of the recommendations proposed to reduce the identified risk level.
\end{abstract}

Keywords: Risk Assessment, Industry, Environment

\section{Introduction}

In the modern world, in keeping with the rapid development of industry and technology, many concerns about adverse consequences of the new technologies on human life have been raised (1). Man-made disasters, such as Feyzin events (France), Mexico City, Piper Alpha and the Flixborough disaster (England), and Chernobyl (Russia), caused due to noncompliance with health, safety, and environment (HSE) standards in industrial activities have recently attracted much attention. This is due to their destructive effects and disruption in the ecosystem caused by environmental pollution (2).
A comparison of major events in different countries, regardless of their level of development, indicates the overlapping and similarity of these events. Factors such as human error, over-reliance on the safety of facilities, unsuitable design, and lack of preparation for critical conditions in developed countries, and non-compliance with HSE standards in the transferring of technology to less developed countries were

\footnotetext{
* Corresponding author: Amaneh Jari, Student Research Committee, Dept. of Occupational Health Engineering, School of Public Health, Gonabad University of Medical Sciences, Gonabad, Iran. Email: ameneh.jari1372@gmail.com
} 
the underlying causes of human and environmental disasters.

All the above factors have caused major disasters in the Iranian industry (3). Today, given the use of complex, inflexible, and expensive technologies, the cost of environmental, human, and economic disaster are often exorbitant (4).

New risk control approaches, particularly in the form of management systems such as ISO14000, OHSAS 18000, and HSE management system (HSE-MS), place more emphasis on preventing accidents rather than managing their consequences. For instance, this issue has been stressed in risk assessment and management as one of the key elements of the Health and Safety Executive. The first step in the process of risk management and assessment is to identify hazards and their effects (5). In this regard, several techniques have been presented, each with their own specific capabilities and limitations, to contribute to the process of identifying hazards and assessing their effects.

Some of these techniques are preliminary hazard analysis (PHA), failure mode and effects analysis (FMEA), fault tree analysis (FTA), and hazard and operability study (HAZOP) (6). The HAZOP was proposed in the late 1960s and developed in the early 1970 s as a practical method of identifying problems in the industrial process of the organic chemical sector in the UK. Today, HAZOP, as a multidisciplinary team approach, is one of the most accurate ways of identifying risk, and is widely used in various industries, especially the chemical industry (7-9). In this technique, which is based on creativity and innovation, people offer their ideas using simulations and brainstorming. In addition, any deviation from the original objective of process design is investigated and the causes and consequences are subsequently identified and eventually controlled (10-12). In this way, process parameters and variables such as temperature, pressure, conductivity, flow rate, service deficiency, and the instrument usage manuals are used as the key components to investigate potential deviations from the main process (13-15).

In the HAZOP technique, models, diagrams, piping, and equipment are analyzed by the team. HAZOP is a brainstorming-based method which can be implemented, based on elements of the safety system, in various forms and is consistent with other methods of risk analysis.

A variety of studies have been undertaken based on HAZOP in power plants, refineries, and chemical industries around the world. Their results have led to the presentation of effective controlling measures, and hence, eradication of potential hazards from the industries. Moreover, the findings have suggested that this method can improve the reliability of industries in system operation (9, 12). In the same line of research, there have been some studies on the analysis of safety issues using HAZOP in Iran, with some of them published in scientific journals or presented at conferences. However, there is still a reactive, post-event view of disaster in Iran, so that investigations and analyses are often undertaken after the occurrence of an accident (16).

Thus, identifying, evaluating, and controlling risks and hazards in industrial environments are of great importance. In addition, multiple chemical processes and material exist in the production of refractory bricks. Therefore, this study seeked to evaluate the risk of refractory brick manufacturing process using HAZOP technique, analyze the potential risks of damage, and identify the results based on the risk level management. This was performed with the aim of proposing effective controlling measures and implementable corrective actions to improve the process and reduce the risk of adverse incidents. In this study, attempts have been made to perform a risk assessment of safety, health and environmental risks in the manufacturing line of the National Company for Distribution of Refractory Products in Gonabad, Iran, using HAZOP techniques. 


\section{Materials and Methods}

This research used a case study to identify and assess qualitative risk. The data collection method consisted of technical and documents analysis and interviews with staff and experts. This study was carried out in 2014 for an 8month period in the refractory brick production factory in the city of Gonabad. The factory uses modern technology for the production of basic refractory products such as magnesite-carbonic, magnesite-spinel, magnesite-aluminum, magnesite, chromite, magnesite, and chromite bricks. It also produces especial firebrick materials, especially spraying and beating masses, tundish covers, and refractory mortars and soil with different aggregation. Bricks are produced through mixing raw materials in the mixer and compressing them with the press machine, passing materials through a dryer to absorb the extra humidity, and finally putting them in a furnace to be baked.

In this study, all the documents required for the evaluation, including drawings, operation and system design, piping and instrument diagrams, specifications and descriptions of system components, were collected with the coordination of the factory director. They were presented to the team members after preliminary analysis by the researchers and safety officers.

For the purposes of this study, the process nodes were identified and evaluated using HAZOP technique. Process nodes included extracting raw materials, loading and mixing materials in the crusher and grinder, transferring materials from the mills to the silos, transferring through different plates to exit from the outlet hopper on the first floor (preparation tower), loading from the first floor hopper, transferring to the press machine, carrying by transporter and storing the bricks in the depot, transferring bricks from the press machine to the furnace (dryer, tunnel furnace, and tempering), removing bricks from the furnace, packaging, and storage (including forklifts).
In this way, the risk level is determined in a three-phase process as follows, and the results are presented in HAZOP worksheets.

1) Determination of the likely consequences of deviations on a scale of $0-10$ from rare to highly probable

2) Determination of the severity of the disaster on a scale of 0-10 from catastrophic to dangerous

3) Determination of the probability of detection on a scale of 0-10 from the absence of any tracking system or operator to the automatic control system equipped with alarms and real-time control system and operator.

For access to detailed information about each of the above phases, see references 2 and 6 . Each of the three sections is determined by multiplying numbers and given a number between 1 and 1000 indicating the importance of the risk.

The HAZOP technique is an effective and systematic method of identifying risks and operational system problems and determining their effects. It is often used in the chemical industry. It is based on the principle that "a system is assumed to be safe when all of its operating parameters such as temperature, pressure, and etc. are at normal and acceptable range." In this method, a team of experts, using a series of keywords, investigate the possible deviations from the standard situations and their likely impacts $(11,13,17)$. The implementation process of the HAZOP technique used in this study is presented in figure 1.

Moreover, the risk of hazards was determined using the probability of occurrence, the severity of impact, and likelihood of detection based on the identification and assessment of risk in hazardous area. To quantitatively measure the risk of identified hazards, equation 1 together with probability of occurrence, the severity of impact, and likelihood of detection were used.

Equation (1) (likelihood of detection) * (probability of occurrence) * (severity of impact $)=$ Risk 


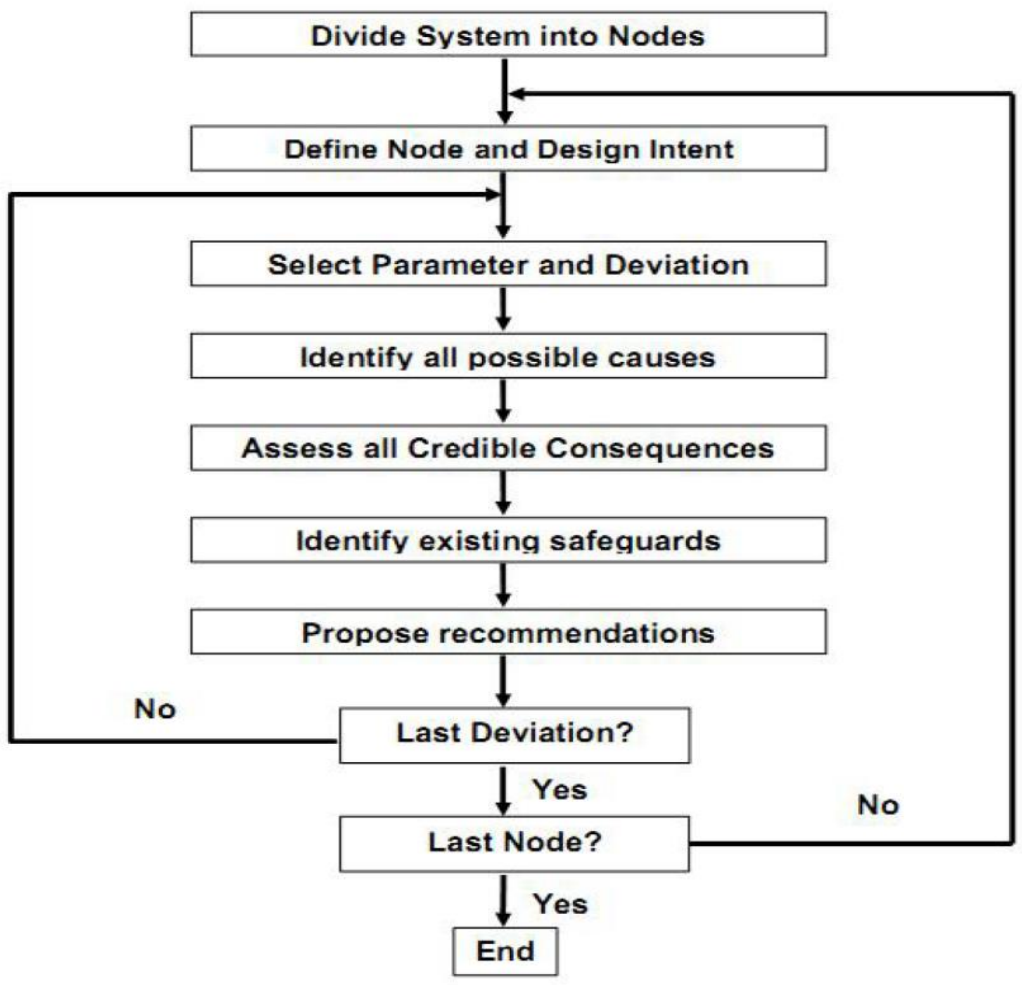

Figure 1: A flowchart of the hazard and operability (HAZOP) technique $(11,13,17)$

The keywords are summarized in table 1 . The operating parameters used in this study consist of product flow, product pressure in the pipelines and storage, product temperature inside pipes and tanks, water accompanying the products, gas accompanying the products, and height variation.
After obtaining the values of probability of occurrence, severity of impact, and likelihood of detection, they are multiplied. By comparing the resulted values with the values displayed in table 2 , the risk measure is achieved. The risk measure is used for making decisions about the identified risks.

Table 1: Keywords used in the hazard and operability (HAZOP) study

\begin{tabular}{cl}
\hline Keywords & Deviations, descriptions, and examples \\
\hline None & The physical process is not performed, for example, there is no stream \\
\hline More than & The physical properties are more than their standard levels. For example, the pressure has been over-defined. \\
\hline Less than & Physical properties are less than their standard level. For example, the temperature has been under-defined. \\
\hline As well as & There are other cases beside the defined cases. For example, the gas stream contains droplets of liquid. \\
\hline Part of & The process combination is different from the standard combination. \\
\hline Reverse & The process outcomes are contrary to the defined goals. For example, the flow is reversed. \\
\hline Other than & Sometimes abnormal operations occur. For example, instead of slowing down, the speed increases.
\end{tabular}

\section{Results}

The results of the HAZOP technique for each node are recorded in the related worksheets. Due to the large number of tables, only some instances of important deviations are presented in table 3. Overall, a total of 6 nodes were identified and explained. The focus of the research team was mainly on operational problems. That is, the causes of deviations that had left adverse effects on system performance 
and had imposed significant economic losses

and personal damages were examined.

Table 2: Decision-making criteria based on risk measure

\begin{tabular}{cl}
\hline Risk Criteria & Criteria Risk Index \\
\hline Unacceptable & $\begin{array}{l}\text { The score of severity impact and liklihood of detection was } 9 \text { and higher and score of } \\
\text { probability of occurrence was } 8 \text { or higher. The risk was greater than 500. }\end{array}$ \\
\hline Undesirable & $\begin{array}{l}\text { The score of the severity of impact was between } 7 \text { and } 8, \text { the score of liklihood of } \\
\text { detection was } 7, \text { and the score of probability of occurrence was } 6 . \text { The risk was } \\
\text { between } 100 \text { and } 500 .\end{array}$ \\
\hline $\begin{array}{c}\text { Acceptable but in } \\
\text { need of revision }\end{array}$ & The risk was between 50 and 100. \\
\hline Acceptable & The risk was less than 50. \\
\hline
\end{tabular}

A total of 97 deviations were identified in this study. The node of extracting, loading, and mixing raw materials in crushers and grinders was responsible for $10.30 \%$ of deviations. The node of transferring materials from mills to silos, transferring from plates to the first-floor outlet hopper (preparation tower) was the cause of $15.52 \%$ of deviations. Moreover, $17.52 \%$ of deviations were related to the node of extraction from hopper in the first floor, and transfer to the press machine, and then, to their depot in the storage line. In addition, 37.113\% of deviations belonged to the node of transferring bricks from press machine to the furnace (dryer, tunnel furnace, and tempering). The node of removing bricks from the furnace, packaging (sharing), and storage (considering the forklifts) was the cause of $15.463 \%$ of deviations. Furthermore, $1.03 \%$ of deviations belonged to the node of product loading (Figure 2).

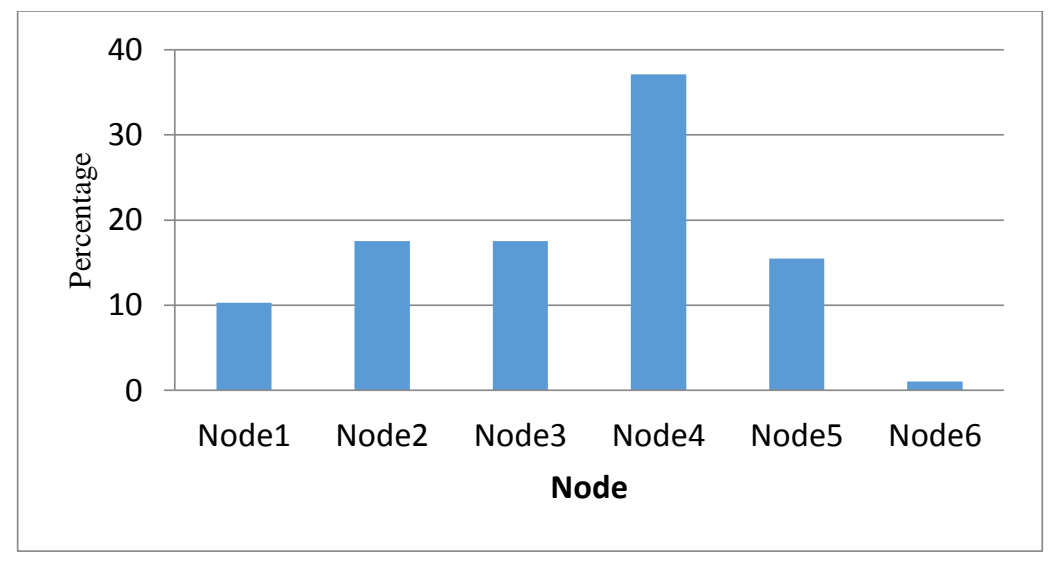

Figure 2. Frequency percentage of nodes

As the results show, a deviation can have multiple causes and consequences. The most important of these include a desire for instant completion of work, absence of a monitoring system, unclean material charging path, wornout equipment, fuel flow cut-off, blockage of torch control valve, defects in the equipment, excessive input of materials, the closure of oil pipe, disregard for the standards, an object stuck in the course of transfer rails, hot air suction pump failure, wagon wheel failure, disruption of air flow required for burning gas, exhaust fan failure, interruption of gas inlet channel, electrical fuse failure, and broken sharing machine rollers. 
Table 3: Hazard and operability (HAZOP) completed worksheet

\section{Team members: Amene Jari and Zahra Jamali}

Analyzed node: transmission of bricks from press machine to the furnace (dryer, tunnel furnace, and tempering)

\begin{tabular}{|c|c|c|c|c|c|c|c|c|c|c|}
\hline No. & $\begin{array}{c}\text { Key } \\
\text { words }\end{array}$ & Deviation & Cause & $\begin{array}{c}\text { Effects or } \\
\text { consequences }\end{array}$ & $\begin{array}{c}\text { Current } \\
\text { control } \\
\text { measures }\end{array}$ & $\begin{array}{l}\text { Corrective } \\
\text { control } \\
\text { measures } \\
\text { (recommend } \\
\text { ed) }\end{array}$ & $\begin{array}{l}\text { Occurren } \\
\text { ce } \\
\text { Probabili } \\
\text { ty }\end{array}$ & $\begin{array}{c}\text { Severi } \\
\text { ty } \\
\text { impact }\end{array}$ & $\begin{array}{l}\text { Detection } \\
\text { probability }\end{array}$ & $\begin{array}{l}\text { Risk } \\
\text { No. }\end{array}$ \\
\hline 1 & $\begin{array}{l}\text { More } \\
\text { than }\end{array}$ & $\begin{array}{c}\text { Temperatur } \\
\text { e in the } \\
\text { funnel } \\
\text { furnace }\end{array}$ & $\begin{array}{l}\text { Operator's } \\
\text { fault } \\
\text { defect in } \\
\text { the } \\
\text { furnace } \\
\text { temperatu } \\
\text { re control } \\
\text { system }\end{array}$ & $\begin{array}{c}\text { 1. Brick } \\
\text { melting } \\
\text { 2. Brick } \\
\text { fragility } \\
\text { 3. Economic } \\
\text { loss } \\
\text { 4. Damage to } \\
\text { the furnace } \\
\text { 5. Wagon } \\
\text { wheel failure } \\
\text { and its } \\
\text { stoppage in the } \\
\text { furnace } \\
\text { 6. Fire and } \\
\text { explosion } \\
\text { hazard } \\
\text { 7. Exposure to } \\
\text { heat stress in } \\
\text { hot seasons for } \\
\text { staff working } \\
\text { near the } \\
\text { furnace }\end{array}$ & $\begin{array}{c}\text { System } \\
\text { control } \\
\text { automati } \\
\text { on and } \\
\text { system } \\
\text { plan }\end{array}$ & $\begin{array}{l}\text { Risk analysis } \\
\text { is carried out } \\
\text { periodically }\end{array}$ & 2 & 4 & 1 & 8 \\
\hline 2 & None & $\begin{array}{l}\text { Smoke } \\
\text { suction of } \\
\text { the furnace } \\
\text { (suction } \\
\text { action) }\end{array}$ & $\begin{array}{l}1 . \\
\text { Channel is } \\
\text { closed } \\
\text { 2. Exhaust } \\
\text { fan failure }\end{array}$ & $\begin{array}{l}\text {-Dense smoke } \\
\text { in the furnace } \\
\text { that reduces the } \\
\text { quality of } \\
\text { bricks } \\
\text {-The risk of } \\
\text { personnel } \\
\text { poisoning in } \\
\text { the salon }\end{array}$ & $\begin{array}{l}\text { Periodic } \\
\text { control } \\
\text { of the } \\
\text { system } \\
\text { gas and } \\
\text { air } \\
\text { control }\end{array}$ & $\begin{array}{l}\text {-Installing } \\
\text { CO detectors } \\
\text { near furnace } \\
\text {-Installing a } \\
\text { secondary } \\
\text { ventilation } \\
\text { system }\end{array}$ & 5 & 3 & 1 & 15 \\
\hline 3 & None & $\begin{array}{l}\text { The air } \\
\text { required to } \\
\text { cool down } \\
\text { the torch } \\
\text { nozzle }\end{array}$ & $\begin{array}{l}\text { Fan path } \\
\text { blockage } \\
\text { or fan } \\
\text { failure }\end{array}$ & $\begin{array}{l}\text {-The torch } \\
\text { nozzle may } \\
\text { remain hot and } \\
\text { there is the } \\
\text { possibility of } \\
\text { torch failure or } \\
\text { its melting } \\
\text {-economic loss }\end{array}$ & $\begin{array}{l}\text { Controlle } \\
\mathrm{d} \text { by the } \\
\text { system } \\
\text { furnace } \\
\text { automati } \\
\text { on }\end{array}$ & $\begin{array}{l}\text { Installing a } \\
\text { secondary } \\
\text { system } \\
\text { (redundancy) }\end{array}$ & 5 & 1 & 1 & 5 \\
\hline 4 & Increase & $\begin{array}{l}\text { The output } \\
\text { rate of brick } \\
\text { from the } \\
\text { tunnel } \\
\text { furnace }\end{array}$ & $\begin{array}{l}\text { Careless } \\
\text { workers } \\
\text { increased } \\
\text { productio } \\
\text { n speed }\end{array}$ & $\begin{array}{l}\text { Infiltration of } \\
\text { phenol gas in } \\
\text { the factory } \\
\text { environment } \\
\text { (risk of } \\
\text { respiratory } \\
\text { toxicity), } \\
\text { which reduces } \\
\text { the brick } \\
\text { quality) }\end{array}$ & $\begin{array}{l}\text { Controle } \\
\text { d by a } \\
\text { monitori } \\
\text { ng } \\
\text { system }\end{array}$ & $\begin{array}{l}\text { Installing } \\
\text { real-time } \\
\text { phenol } \\
\text { monitor or } \\
\text { periodic } \\
\text { monitoring }\end{array}$ & 5 & 3 & 1 & 12 \\
\hline
\end{tabular}

Furthermore, in this study, the risks were classified based on the type of hazard, with $6.01 \%$ of hazards belonging to physical risks, $29.16 \%$ to mechanical hazards, $4.62 \%$ to chemical hazards, and $50.92 \%$ to other combined hazards (Figure 3). The highest rate of failures in the study to stop production were due to gas fuel valve pack or a significant 
reduction in gas pressure in the furnace, failure in connecting the tempering furnace, and electric furnace defect control module with the risk rate of 144,120 , and 108 , respectively.

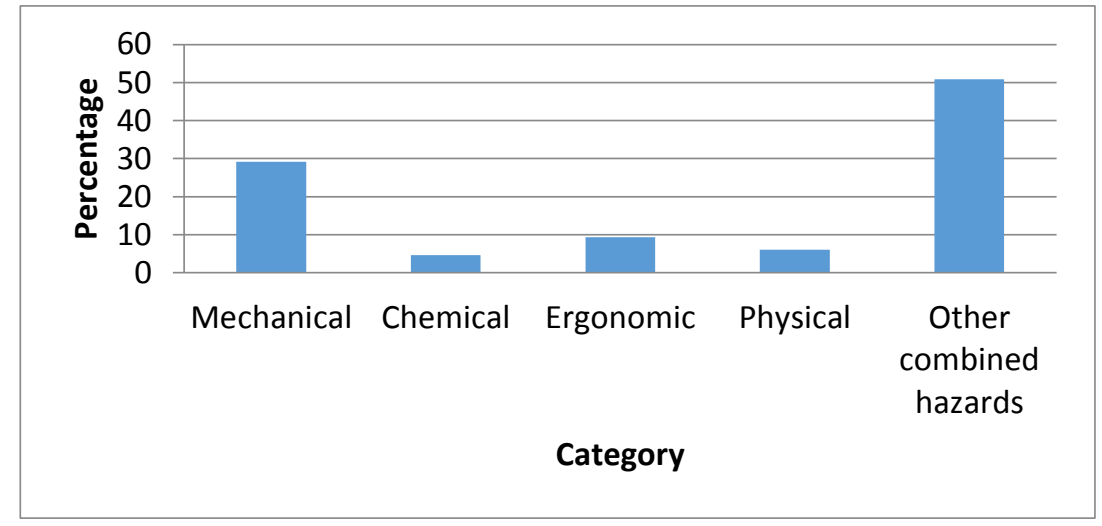

Figure 3. Frequency percentage of hazards

The results of the study classification suggested that based on the probability of occurrence, $50.51 \%$ ranked $1-3,45.35 \%$ ranked $4-7$, and $12.4 \%$ ranked $8-10$. In addition, in terms of the severity of impact, $92.77 \%$ of the hazards ranked 1-3 (losses less than 100 thousand Tomans to 1 million Tomans), 6.168\% ranked 4-7 (damage over 1 million Tomans to 1 hundred million Tomans), $1.03 \%$ ranked 8-10 (the loss of over 1 hundred million Tomans to over 1 billion Tomans). Furthermore, it was found that with respect to the likelihood of detection, $8.35 \%$ ranked $1-3$, $16.493 \%$ ranked $4-7$, and $6.153 \%$ ranked $8-10$.

\section{Discussion}

The HAZOP technique as a comprehensive hardware method has a number of advantages such as desirable performance in complex systems and provision of accurate results.
Some disadvantages of HAZOP include timeconsuming execution, high-cost implementation, and tedious performance. Moreover, it fails to troubleshoot multiple and multistage faults. Given the purpose of the study, after a detailed introduction to the process, mechanical equipment, and precise devices, and active communication between team members and reception of their feedbacks, many of the risks were identified and analyzed by team members.

As mentioned, the results of this study yielded 97 deviations from the main process with their respective causes and consequences. None of the deviations belonged to the unacceptable category, $3.09 \%$ to the category of acceptable but in need of revision, $3.09 \%$ to the undesirable category, and $92.78 \%$ to the acceptable category. The results for each risk level are presented in figure 4.

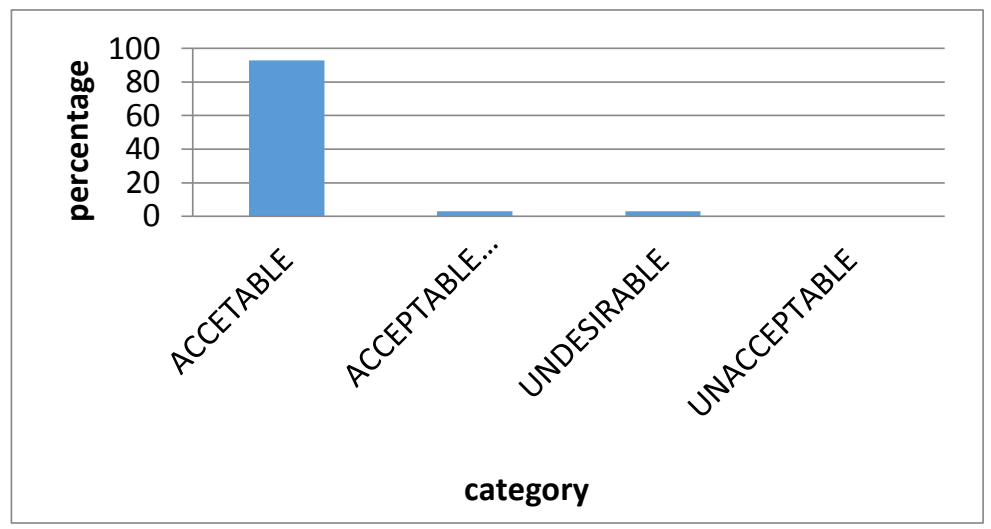

Figure 4. Frequency percentage of identified risk categories 
Deviations in the fourth node [transmission of bricks from press machine to the furnace (dryer, tunnel furnace, and tempering furnace)] were more than other nodes. Undesirable risks were only observed in the first and third nodes. In the fourth node, there were some acceptable but in need of revision risks, which should be taken into account and necessary corrective control measures should be applied accordingly. For a number of the above deviations, some corrective measures have been suggested. In calculating the risk rate of deviations, it must be noted that probably one of the main reasons for the lower rate in risks is due to lack of performance in the data recording system.

Developing a regular manual and periodic repairs and maintenance of the system due to equipment wear-out are recommended in order to avoid deviations. In a study by Angela and Pully, the repairing, adjustment, and increasing of equipment were recommended (18).

Since some recommendations could be applied to various nodes, there was no need to repeat them or state a specific solution for a particular deviation. This is consistent with the literature (19). In the comparison between different groups of control actions, preventive actions usually are lower cost and higher efficiency.

In a study on the identification and assessment of chemical risks in Yazd Combined Cycle Power Plant using HAZOP technique (20), 126 deviations were detected. Unlike the results of our study, their findings showed that some deviations in the power plant fell in the unacceptable category (20).

In addition, the number of undesirable and acceptable but in need of revision deviations in their study was greater than ours, though more deviations fell in the acceptable category in our study (20).

In addition, in study of Mohammadfam et al on the application of the HAZOP technique in the assessment of the safety, health, and environmental risks (Case Study: National Oil
Product Distribution Company), about 1180 risks were identified. Contrary to the results of this study, in the studies by Mohammadfam et al, $38.13 \%$ of the identified risks fell in the unacceptable category with human errors accounting for $31.35 \%$ of risks $(21,22)$.

Ebrahimzadeh evaluated the potential risks in Shiraz Refinery using failure mode effects analysis (FMEA) (23). Their study revealed that the highest risk priority number (RPN) score in the manual material handling and drilling the outer surfaces before and after the implementation of corrective measures was 200-210 and 72-74, respectively, which fell in first category of RPN division. However, the risk priority score in welding and drilling before and after the application of corrective action was 120 and 144, and 24 and 36, respectively, which fell in the first category of RPN division (23).

According to the results, more than half $(52.57 \%)$ of the identified causes were due to the defective performance of the control systems (Figure 5), $40.20 \%$ due to human errors, and $7.21 \%$ due to failures in system equipment.

To control the deviations, a total of 48 technical, managerial, and executive recommendations were presented, though no strategic solution was proposed for some risks. The recommendations were mainly related to equipment modification process (53.06\%), repairing and maintenance of equipment $(10.20 \%)$, and execution of correct operation procedures $(34.69 \%)$. This was relatively similar to the results of the study by Zare on identification and assessment of risks in the chemical unit of the Yazd Combined Cycle Power Plant (20).

In the study by Zare, the recommendations were mainly focused on process equipment modification (42\%), repairing and maintenance of equipment (35\%), and employment of operation procedures $(23 \%)$ (20). 


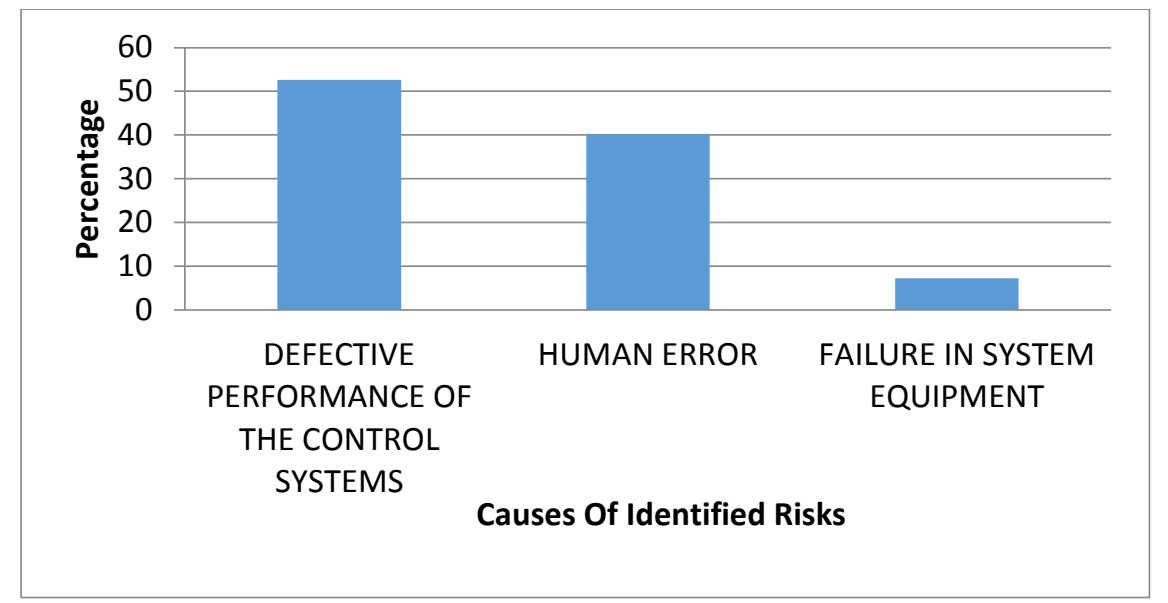

Figure 5. Frequency percentage of identified risks with respect to their causes

\section{Conclusion}

The results showed that one causes of the failures is methods of design and manufacture in the process mentioned which in some cases required by changes in layout and design process. In addition, formulating work manuals for repairs and maintenance can increase the reliability of the system, and hence, prevent potential risks. Moreover, the HAZOP technique can be a very effective way to identify risks in the production line of a refractory brick factory, and thereby, can help in taking the necessary precautions to prevent the occurrence of accidents. In order to evaluate the effect of other factors, such as system quality maintenance, further studies are necessary.

\section{Acknowledgement}

The authors would like to thank all the personnel who participated in this study.

Conflict of interest: None declared

\section{References}

1. Dunjo J, Fthenakis V, Vilchez JA, Arnaldos J. Hazard and operability (HAZOP) analysis. A literature review. J Hazard Mater 2010; 173(13):19-32.

2. Jarvis J. Occupational health and safety: take the first step. Quality World 1997; 23(7):554-6.

3. Mearns K, Whitaker S, Flin R. Benchmarking safety climate in hazardous environments: a longitudinal, inter-organisational approach. Risk Anal 2001; 21(4):771-86.

4. Pidgeon, N, O' Leary M. Man-made disasters: why technology and organizations (sometimes) fail. Saf Sci 2000; 34:15-30.

5. Dillon RL, Pate-Cornell ME, Guikema SD. Programmatic Risk Analysis for Critical Engineering Systems Under Tight Resource Constraints. Oper Res 2003; 51(3):354-70.

6. Bartolozzi V, Castiglione L, Picciotto A, Galluzzo M. Qualitative models of equipment units and their use in automatic HAZOP analysis. Reliability Engineering \& System Safety 2000; 70(1):49-57.

7. Khan F, Abbasi SA. OptHAZOP-an effective and optimum approach for HAZOP study. J Loss Prev Process Ind 1997; 10(3):191-204.

8. De la O Herrera MA, Luna AS, de Costa ACA, Lemes EMB. A structural approach to the HAZOP- Hazard and operability technique in the biopharmaceutical industry. J Loss prev process Ind 2015; 35:1-11.

9. McDermid JA, Nicholson M, Pumfrey DJ, Fenelon P. Experience with the application of HAZOP to computer-based systems. Proceedings of the Tenth Annual Conference Computer Assurance, 1995. COMPASS '95. Systems Integrity, Software Safety and Process Security; 1995 Jun 25-29; Gaithersburg, Maryland, United States of America. Maryland: IEEE; 1995. P 37-48.

10. Swann CD, Preston ML. Twenty-five years of HAZOPs. J Loss Prev Process Ind 1995; 8(6):349-53.

11. Labovsk J, Jelemensky L, Marko J. Safety analysis and risk identification for a tubular reactor using the HAZOP methodology. Chemical Papers 2006; 60(6):454-9.

12. Fencott C, Hebbron BD. The application of HAZOP studies to integrated requirements models for control systems. ISA Trans 1995; 34(3):297-308.

13. Nolan DP. Application of Hazop and What-If Safety Reviews to the Petroleum, petrochemical and Chemical Industries. United States of America: Noyes Publications; 1994.

14. Khan FI, Abbasi SA. TOPHAZOP: a knowledgebased software tool for conducting 
HAZOP in a rapid, efficient yet inexpensive manner. J Loss Prev Process Ind 1997; 10(56):333-43.

15. Redmill F, Chudleigh MF, Catmur JR. Principles underlying a guideline for applying HAZOP to programmable electronic systems. Reliability Engineering and System Safety 1997; 55(3):283-93.

16. Shiral Gh. How to use ETBA technique in the industry? Case study in Tehran Izomax Refinery. [MSc Thesis]. Tehran: Tehran University of Medical Sciences; 2004.

17. Mohammadfam, I. Safety Engineering. Tehran: Fanavaran publication; 2011.

18. Pully AS. Utilizatin and resalt of hazard and operability studies in a petroleum refinery. Process Safety Progress 1993; 12(2):106-10.

19. Shafaghi A, Cook FB. Application of a hazard and operability study to hazard evaluationof an absorption heat pump. Reliability, IEEE Transactions on 1988; 37(2):159-66.

20. Zare M, Baghaei-khah H, Barkhordari A, Zare
Saeid. Identification and assessment of risks in chemical unit of Yazd combined cycle power plant using HAZOP technique. Paper presented at: The 24 international conference on electricity; 2009 Nov; Tehran, tavanir company, power Research Institute.

21. Mohammadfam I, Mahmoudi S, Kianfar A. Comparative safety assessment of chlorination unit in tehran treatment plants with HAZOP \& ETBA techniques. Procedia Eng 2012; 45:2730.

22. Asadi A. The Investigation Hazards Make Accidents in an Oil Refining Company. Paper presented at: First Symposium of Occupational Health and Safety in Oil Refining Companies; 2003;

23. Ebrahimzadeh M, Halvani G, Mortazavi M, \& Soltani R. Assessment of potential hazards by Failure Modes and Effect Analysis (FMEA) method in Shiraz Oil Refinery. Occupational Medicine Quarterly Journal 2011;3(2):16-23. 